\title{
Guest-editorial \\ Post marketing surveillance for implants
}

"The pioneer years are over and the public has a right to be assured that artificial implants do not introduce unexpected hazards associated with poor design, incompatible materials, or deficient manufacturing procedure and quality control"1.

The above quotation dates from the period before the adoption of the Medical Device Directive in 1993. Since 1993, the year in which the first step was put towards a uniform quality regulation system for medical devices, a lot has been changed. New requirements for medical devices with the objective to create the abovementioned assurance for the public have come into force. All manufacturers will have to meet these requirements in order to get the obligatory CE mark for their products.

This CE mark is essential in the market approval process of a medical device. Once the device is on the market, the manufacturer has to meet other requirements regarding the post-production phase, that is, the stage of application and follow-up.

Post marketing surveillance (PMS) is the systematic procedure to review experience gained from devices in the post-production phase. This can be done by recording, reviewing and reporting about this experience.

The essential elements in a PMS-system are:

- patient and implant tracking;

- vigilance;

- retrieval.

However, it must be clear that a well functioning PMS-system can only be established and function well with the cooperation of all actors in the medical device field: manufacturer, surgeon and patient. Also the role of government authorities has to be discussed.

In April 1995, a two day discussion on this important subject took place in Amsterdam. All elements of a PMS-system were studied. The new Directive and its implications for post marketing surveillance were discussed by representatives from government authorities, health care practitioneers, the manufacturers and patient organizations.

We trust that the fruitful discussions that took place will make a contribution to the realization of the above mentioned quotation.

L.M.C. Faro

\footnotetext{
${ }^{1}$ Editorial Acta Orthop. Scand. 58 (1987), 477-478.
} 